\title{
Heterogeneity reduces sensitivity of cell death for TNF-Stimuli
}

Monica Schliemann ${ }^{1}$, Eric Bullinger ${ }^{2^{*}}$, Steffen Borchers ${ }^{1}$, Frank Allgöwer ${ }^{3}$, Rolf Findeisen ${ }^{1}$ and Peter Scheurich ${ }^{4}$

\begin{abstract}
Background: Apoptosis is a form of programmed cell death essential for the maintenance of homeostasis and the removal of potentially damaged cells in multicellular organisms. By binding its cognate membrane receptor, TNF receptor type 1 (TNF-R1), the proinflammatory cytokine Tumor Necrosis Factor (TNF) activates pro-apoptotic signaling via caspase activation, but at the same time also stimulates nuclear factor $\kappa \mathrm{B}$ (NF- $\kappa \mathrm{B}$ )-mediated survival pathways. Differential dose-response relationships of these two major TNF signaling pathways have been described experimentally and using mathematical modeling. However, the quantitative analysis of the complex interplay between pro- and anti-apoptotic signaling pathways is an open question as it is challenging for several reasons: the overall signaling network is complex, various time scales are present, and cells respond quantitatively and qualitatively in a heterogeneous manner.

Results: This study analyzes the complex interplay of the crosstalk of TNF-R1 induced pro- and anti-apoptotic signaling pathways based on an experimentally validated mathematical model. The mathematical model describes the temporal responses on both the single cell level as well as the level of a heterogeneous cell population, as observed in the respective quantitative experiments using TNF-R1 stimuli of different strengths and durations. Global sensitivity of the heterogeneous population was quantified by measuring the average gradient of time of death versus each population parameter. This global sensitivity analysis uncovers the concentrations of Caspase-8 and Caspase-3, and their respective inhibitors BAR and XIAP, as key elements for deciding the cell's fate. A simulated knockout of the NF- $\kappa \mathrm{B}$-mediated anti-apoptotic signaling reveals the importance of this pathway for delaying the time of death, reducing the death rate in the case of pulse stimulation and significantly increasing cell-to-cell variability.

Conclusions: Cell ensemble modeling of a heterogeneous cell population including a global sensitivity analysis presented here allowed us to illuminate the role of the different elements and parameters on apoptotic signaling. The receptors serve to transmit the external stimulus; procaspases and their inhibitors control the switching from life to death, while NF- $\kappa$ B enhances the heterogeneity of the cell population. The global sensitivity analysis of the cell population model further revealed an unexpected impact of heterogeneity, i.e. the reduction of parametric sensitivity.
\end{abstract}

\section{Background}

Apoptosis is a cellular program essential for maintaining homeostasis in multicellular organisms. It represents the most common form of physiological cell death [1-4]. Tight control of apoptotic signaling is essential, as its downregulation may lead to cancer or autoimmune diseases [5,6]. Contrarily, atrophy, as in ischemic damage

\footnotetext{
* Correspondence: e.bullinger@ulg.ac.be

${ }^{2}$ Department of Electrical Engineering and Computer Science, Institut Montefiore, Université de Liège, Belgium

Full list of author information is available at the end of the article
}

or neurodegenerative disorders such as Alzheimer's, Huntington's, and Parkinson's diseases, is characterized by excessive apoptotic activity [7-9]. Apoptosis can be induced by intrinsic and extrinsic signaling pathways that are highly regulated and interconnected and can be counteracted by anti-apoptotic signal pathways [10]. Thus, obtaining insights into the complex regulatory network related to apoptosis is important, yet challenging. Here we use a global sensitivity analysis on an experimentally validated cell ensemble model to illuminate apoptosis signaling. 
An important extrinsic mediator of apoptosis is the cytokine Tumor Necrosis Factor (TNF). TNF exhibits potent antitumoral activity, but also represents a major activator of innate immune responses with strong proinflammatory and pathophysiological activities [11]. Soluble TNF interacts with and activates the membrane receptors TNF receptor type 1 (TNF-R1, CD120a, p55/ 60 ), whose activation triggers different cellular responses, including two seemingly contradictory ones. On the one hand, TNF-R1 induces cell proliferation by activating the transcription factor NF- $\kappa \mathrm{B}$ [12]. On the other hand, internalized TNF-R1 initiates programmed cell death through the activation of initiator caspases $[13,14]$. There exists a second cell membrane receptor specific for TNF, called TNF-R2 (CD120b, p75/80), but this receptor can be activated only by the membrane integrated preform of TNF [15] and is not taken into account here.

The present study was performed with KYM-1 cells, a human rhabdomyosarcoma derived cell line, not affected in TNF sensitivity by overexpression of either bcl-2 or bcl-xl [16]. Therefore, apoptosis occurs independently of the mitochondrial pathway, and thus KYM-1 represents a model for TNF-induced apoptosis in so-called type 1 cells [17]. Another advantageous property of KYM-1 cells, in contrast to most other cell lines, is their high sensitivity to the apoptotic effects of TNF, even in the absence of a metabolic or DNA synthesis inhibitor [18]. As a consequence, apoptosis develops rapidly in these cells.

The reaction network considered here is schematically depicted in Figure 1 and consists of three modules: the TNF-R1 receptor signaling complex (green background), the NF- $\kappa \mathrm{B}$ pathway (blue background) and the caspase activation pathway (red background). The pro- and antiapoptotic TNF-R1 signaling pathways are internally and mutually regulated via feedback loops leading to a highly complex and dynamic behavior. Obviously, the fine-tuning of the intracellular signaling pathways' regulatory circuits dictates the resulting cellular response (cell death or survival) in the end.

A key feature of the apoptotic program is its switchlike behavior, where the transition from life to death is rapid and not synchronized within a population of clonal cells [19]. Cell-to-cell variability is a hallmark of many biological phenomena, not only in induction of apoptosis [20], but also in adaptivity [21], immune response [22], stress response [23], differentiation and development [24] and cancer cell drug resistance [25]. Cell-to-cell variability can lead to different qualitative behavior at the single cell level but also in cell populations, in particular in systems showing bistability (all-ornothing effects) or oscillatory behavior $[26,27]$. Causes for the intercellular heterogeneity can be stochastic fluctuations or deterministic, such as genetic/epigenetic differences or differential cell cycle phases. For human cells, protein levels of most signaling networks remain constant over several days [28] as they are tightly regulated [29]. Therefore, it seems reasonable to assume that life-death decisions of individual cells are executed on a deterministic basis.

Investigation of the complex, dynamic and highly regulated integration of TNF-induced pro and antiapoptotic signals is facilitated by mathematical modeling based on the combination of quantitative and dynamic experimental data with mathematical modeling [30]. This abstraction helps testing hypotheses and provides insight into the governing mechanisms and their quantitative and dynamic features [31], which can be particularly intricate in apoptosis signaling [32]. Also see [33] for a review of apoptosis modeling.

A modeling framework for cell-to-cell variability is the cell ensemble modeling approach. This combines a large number of individual (cell) models that differ in some key parameters. This approach is particularly suitable for the description of unsynchronized cell cultures as it allows for the reproduction of the behavior of both single cells as well as whole cell populations. Successful application examples in the literature focus on heterogeneous cultures of E. coli growth [34], yeast metabolic oscillations [35] as well as TRAIL-induced apoptosis [20].

This study analyzes the competing pro and anti-apoptotic TNF signaling pathways with their crosstalk mechanisms within a heterogeneous cell population. The experimentally validated cell population model enables us to analyze the dynamics of TNF-R1 responses in more detail than would be possible by experiments alone. Results from this study underline the importance of the stimulus duration for the resulting cellular phenotype and the particular importance of the receptor concentration for the time of death development, as well as of NF- $\kappa \mathrm{B}$ for cell-to-cell heterogeneity regarding the time of death. The analysis required defining a novel global sensitivity measure for heterogeneous populations: the linearized dependency of the time of death versus each population parameter. The sensitivity analysis of the cell population revealed that the nominal cell is much more sensitive than the cell population. The performed model analyses highlight the necessity, for a heterogeneous population, of quantifying the sensitivity on the population level, and not just of the nominal cell, even though this is much more convenient, computationally speaking.

\section{Results}

The result section is structured as follows. First, experimental data on the time and dose dependency of TNF- 


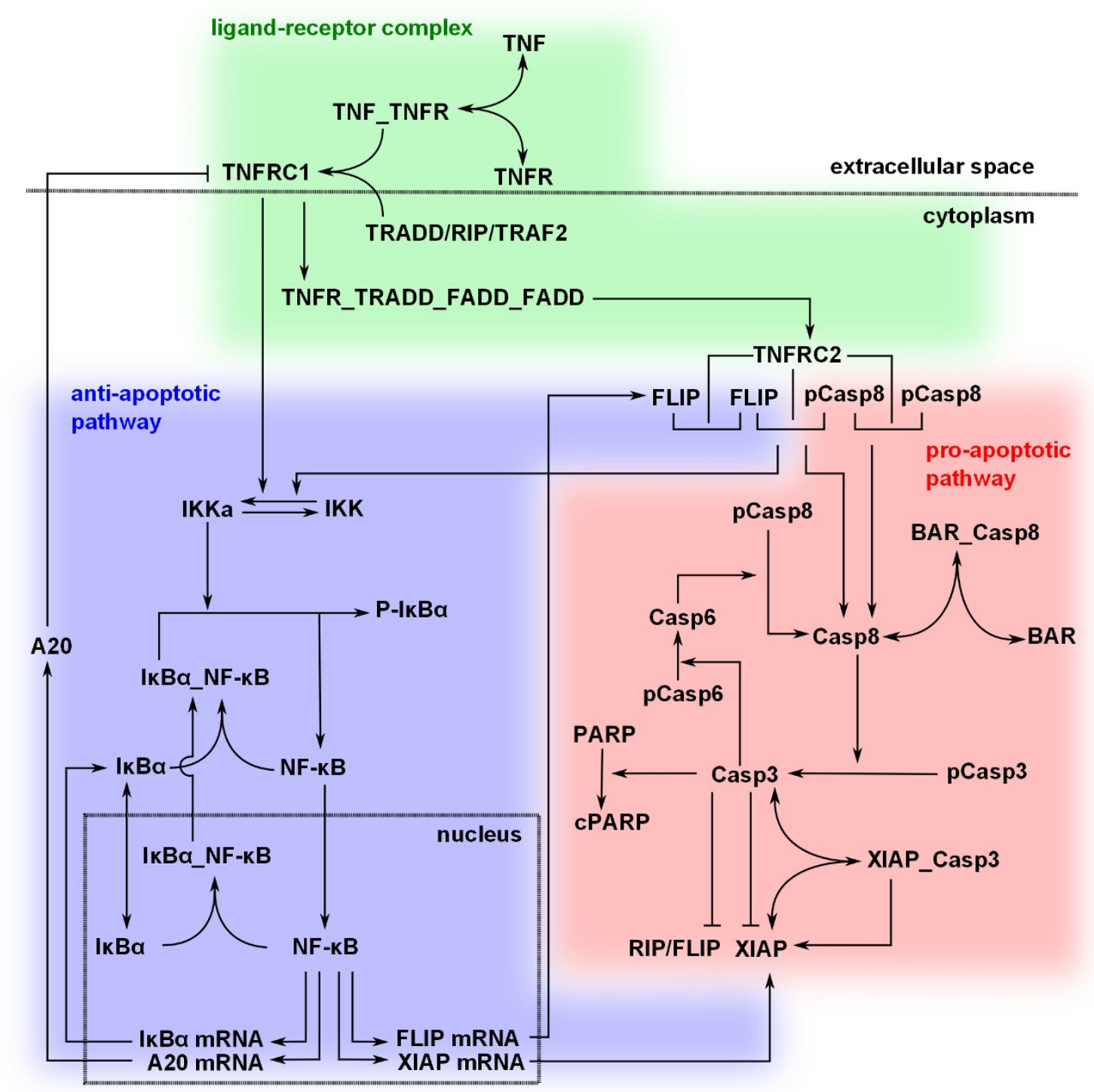

Figure 1 Illustration of the Signaling Pathways and Interactions Initiated by TNF-R1. Ligand stimulated TNF-R1 activates two major signaling pathways, pro- and anti-apoptotic cellular responses (red and blue background, respectively). The ligand-receptor interaction and signal complex formation is outlined in the green area.

R1-mediated signaling are shown. This led to the development of a cell ensemble model. Then, we present a model-based sensitivity analysis of the time of death, before concluding with an analysis of the NF- $\kappa \mathrm{B}$ module on the heterogeneity within the population using insilico knockout cells.

Time and Dose Dependency of TNF-R1-mediated Cellular Responses

Two important outputs of TNF-R1 signaling are the concentration of nuclear NF- $\kappa \mathrm{B}$ and Caspase- 3 activity. As NF- $\kappa \mathrm{B}$ induces the expression of the caspase inhibitors XIAP and FLIP, it serves as a marker of the anti- apoptotic cell response. The experimental data on the concentration of active nuclear NF- $\kappa \mathrm{B}$ indicated a rapid activation after stimulation with $10 \mathrm{ng} / \mathrm{ml}$ TNF (Figure $2 \mathrm{~A})$. For pulse stimulations, the $\mathrm{NF}-\kappa \mathrm{B}$ activity decreased after 1 hour, while it remained at a high level for continuous stimulations. The experiment shown in Figure 2A is representative for 11 different experiments, where cells had been stimulated with $0.3,1$ or $10 \mathrm{ng} / \mathrm{ml}$ TNF given either as a 30 minute pulse or continuously. These experiments consisted of 12-18 measurements each, with a total of 186 data points.

Caspase- 3 activity increased over a time window of several hours (Figure 2B). Similarly, the quantification of 
cell viability over time revealed that the apoptotic response developed significantly later, occurring no earlier than 3 hours post stimulus (Figure 2C and 2D). A sigmoid correlation between TNF stimulus strength and viability could be observed: higher TNF concentrations resulted in earlier cell death and higher cell death rates (Figure 2C and 2D, see also Additional File 1 showing the same data in 2D panels). Differences between pulse and continuous TNF stimulation were most visible at intermediate concentrations (1-10 $\mathrm{ng} / \mathrm{ml} \mathrm{TNF})$, where a TNF pulse did not induce significant apoptosis, whereas continuous stimulation did (Figure 2C). However, even for nearly saturating TNF concentrations $(\geq 30 \mathrm{ng} / \mathrm{ml})$, continuous TNF stimulation led to a faster response and higher death rate as compared to a respective TNF pulse (Figure 2D). For very low TNF concentrations $(\leq 0.1 \mathrm{ng} /$ $\mathrm{ml}$ ), neither a continuous nor a pulse TNF treatment induced significant apoptosis.

The sigmoidal dose response and the different time scales highlighted the complexity of the TNF-induced signaling. To gain further insight into the regulatory mechanisms of this system, we first developed a mechanistic single cell model of TNF induced pro and anti-apoptotic signaling describing the signal transduction within a median cell. The model structure corresponds to the pathway shown in Figure 1. See Additional File 2 for a detailed description of the model and Additional File 3 for its SBML code.

To illustrate the model behavior, we performed time course simulations of the nominal cell model over 16 hours post stimulus with TNF concentrations ranging from 0.01 to $100 \mathrm{ng} / \mathrm{ml}$, both for continuous (Figure
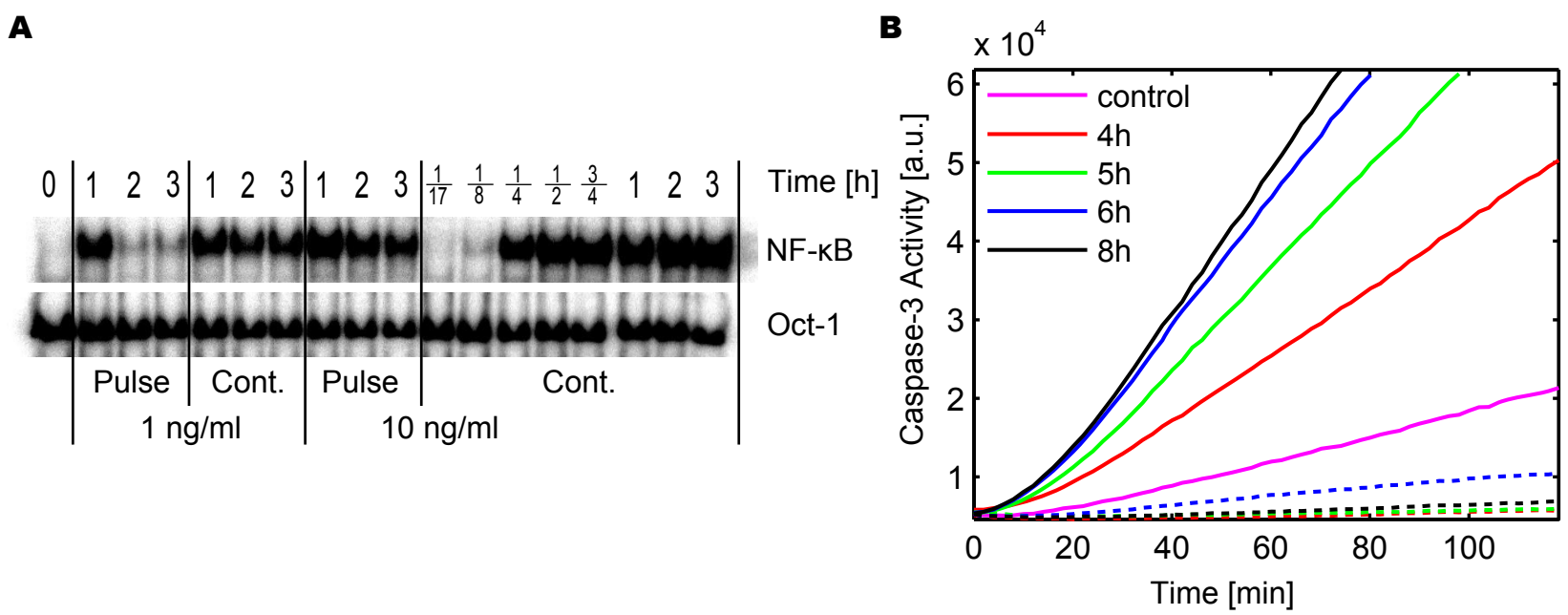

C

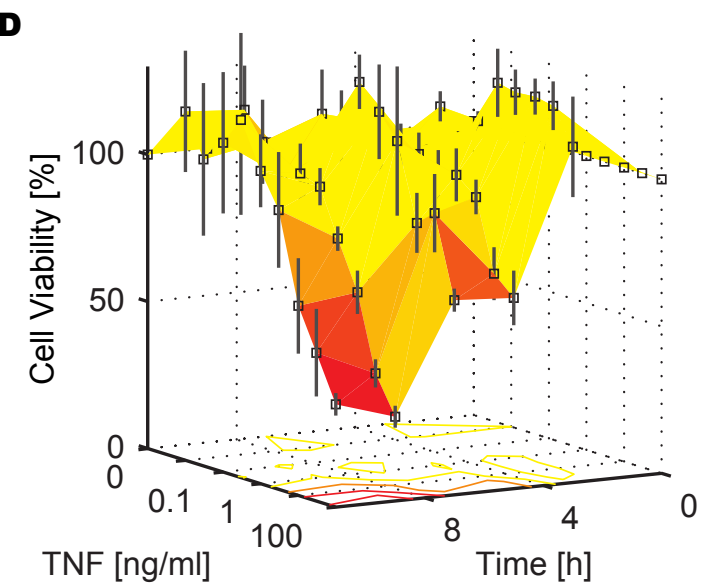

Figure 2 Experimentally obtained Dynamic Dose-Responses. (A) NF- $\kappa$ B in the nucleus after $1 \mathrm{ng} / \mathrm{ml}$ and $10 \mathrm{ng} / \mathrm{ml}$ TNF for 30 minute pulse or continuous stimulation, as shown by EMSA at different time points. Oct-1 served as loading control. (B) Caspase-3 activity assay for continuous stimulation of $1 \mathrm{ng} / \mathrm{ml}$ TNF (solid lines) measured 4-8 h post stimulus. Control experiments without TNF (magenta) and with the caspase inhibitor Z-VAD-fmk (dashed lines). (C) and (D) Cell viability over time for 10 different TNF concentrations (0-100 ng/ml TNF). The surfaces connect the measured data points. Continuous (C) and 30 minute pulse (D) stimulations, both including error bars from three independent experiments. The isoclines (lines connecting points of same cell viability) are shown projected onto the $0 \%$ planes. 
3A) and 30 minute pulse stimulations (Figure 3B). NF$\kappa \mathrm{B}$ was rapidly activated even at low TNF concentrations, and converged to a higher activation level in the case of a continuous TNF stimulation (Figure 3A versus Figure $3 \mathrm{~B})$. For both types of stimuli, Caspase-3 activation occurred after a delay of a few hours with a switching duration of only a few minutes. TNF pulse stimulations resulted in later responses of Caspase-3 activation, and no activation at all was observed for the lowest concentration range. Interestingly, a higher TNF stimulus led to a higher and an earlier NF- $\kappa$ B translocation as well as earlier Caspase-3 activation.

The experimental data presented in Figure 2 were based on averaging measurements of a population of cells. To reproduce this data, we established a mathematical model of a cell population in the form of a cell ensemble model, in which all production rates were lognormally distributed within the cell population, see Additional File 2. For a specific stimulus, the qualitative response varied between individual cells of the cell population: some cells survived, some died with a time of death from 2 hours post stimulus onwards, where cell death is defined as the time point of $50 \%$ cleavage of the Caspase- 3 substrate PARP. The cell ensemble model was validated using cytotoxicity assays at various concentrations of TNF as well as using Western blotting, caspase activity assays and microinjection experiments, see Additional File 2.

\section{Sensitivity of the Time of Death}

To gain a deeper understanding of the importance of the different parameters, we studied the sensitivity of the time of death with respect to the population parameters. As a global sensitivity measure, we defined the slope of the linear approximation of time of death versus each population parameter on a log-log plot. Figure 4 depicts the projection of the time of death of individual cells with respect to three of the population parameters (production rate of TNF receptor, $\mathrm{I} \kappa \mathrm{B} \alpha$ mRNA expression and XIAP production). The linear approximation obtained using robust linear regression is shown as solid black lines. Its slope is our global sensitivity measure. As TNFR had a negative slope, the more TNFR was produced the earlier the cells died. XIAP, on the other hand, had a positive slope, thus more XIAP delayed cell death. For $\mathrm{I} \kappa \mathrm{B} \alpha$, no clear trend was visible.

Figure 5 shows the value of the global sensitivity measure for each one of the 19 distributed parameters, in a population of 2500 cells stimulated in silico with $10 \mathrm{ng} /$ $\mathrm{ml}$ TNF, either continuously (Figure 5A) or applied as a 30 minute pulse (Figure 5B). In both cases, the sensitivity of the cell population was compared to the sensitivity analysis performed on the nominal cell using a multiplicative perturbation of 1.1 , increasing and decreasing each parameter. While in many cases the results of nominal and cell population sensitivity were similar, there were significant differences, particularly for pulse stimulations. There, several nominal sensitivities were significantly higher than the corresponding sensitivity of the cell population, see especially TNFR, RIP, TRAF2, Procaspase- 8 and BAR.

Analyzing the cell population sensitivity revealed that the parameters can be divided into three groups. In the

\section{$\mathbf{A}$}

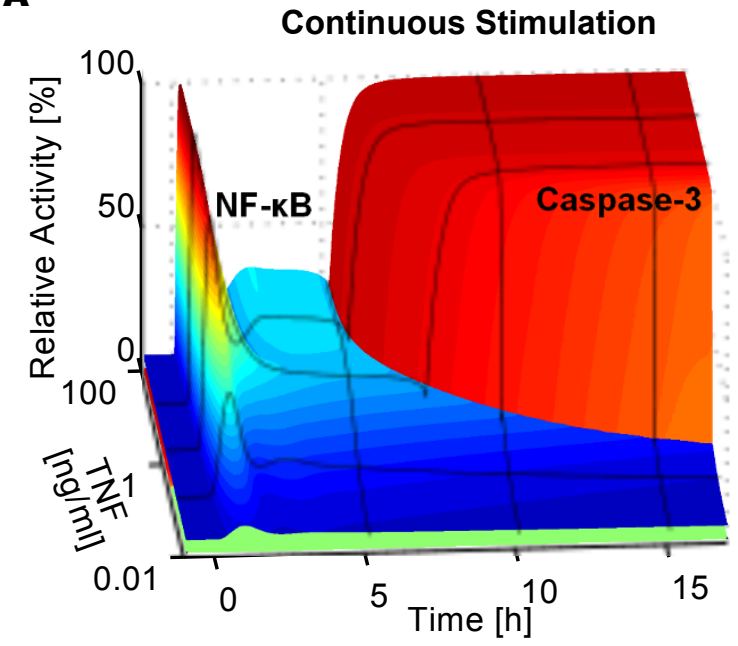

B

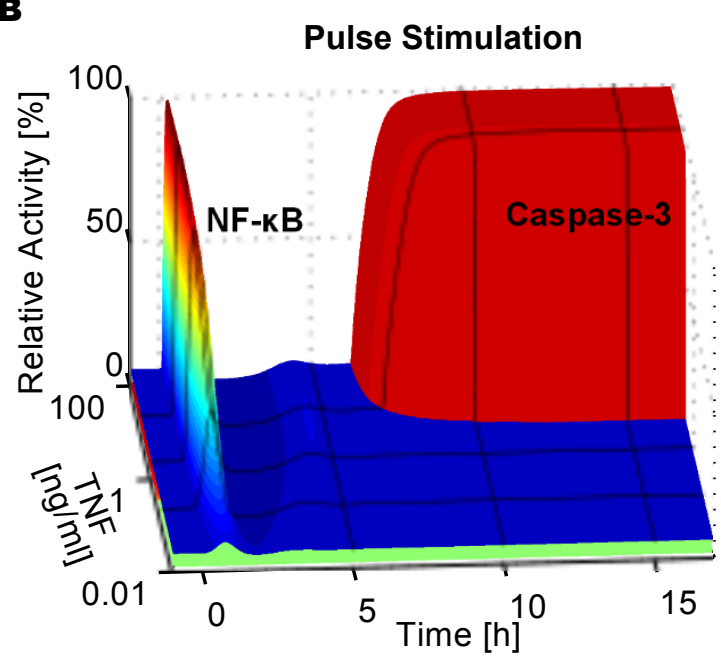

Figure 3 Simulations of the Single Cell Model. (A) and (B) Single cell time course simulations of relative NF- $\kappa$ B translocation into the nucleus and Caspase-3 activation for TNF concentrations in the range of $0.01-100 \mathrm{ng} / \mathrm{ml}$; (A) for continuous TNF stimulation and (B) for 30 minute TNF pulse stimulation. Relative activities represent the concentration time courses divided by their maximum values. For $\mathrm{NF}-\kappa \mathrm{B}$, the relative activity is color coded such that blue depicts a low, yellow a medium and red a high nuclear accumulation. For Caspase-3, the color of a complete trajectory stands for the time of death: early death in red, late death in yellow, cell survival in green. 


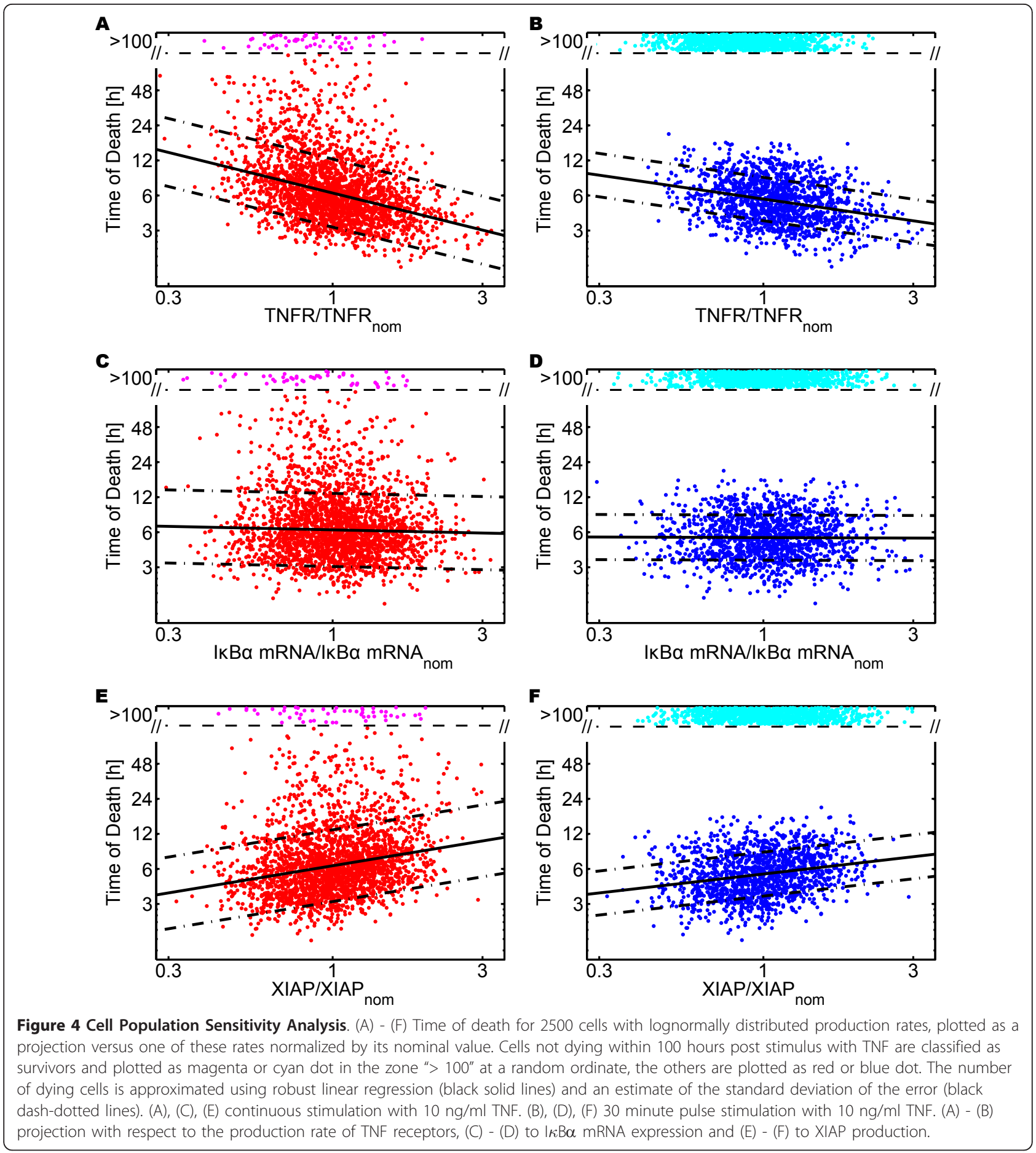

first one, an increase of the parameter resulted in later death. Members of this group are the caspase inhibitors XIAP and BAR. Members of the second group caused the opposite effect: a larger parameter value correlated with earlier death. This group includes the TNF receptor and its adaptor proteins RIP, TRAF2, as well as the Procaspases -3 and -8 . The remaining parameters had little impact on the time of death. Most parameters exhibited similar sensitivities for continuous and pulse stimulation, even though cell death was delayed in the nominal case by approximatively 3 hours for a $30 \mathrm{~min}$ ute pulse compared to the respective continuous stimulation. Different sensitivities for pulse and continuous stimulation were only visible for TNFR, RIP, TRAF2 
Table 1 Impact of the NF- $\kappa$ B Pathway

\begin{tabular}{llllll}
\hline & TNF & $\mathbf{3 0} \mathbf{n g} / \mathbf{m l}$ & $\mathbf{1 0} \mathbf{n g} / \mathbf{m l}$ & $\mathbf{3} \mathbf{n g} / \mathbf{m l}$ & $\mathbf{1} \mathbf{n g} / \mathbf{m l}$ \\
\hline \multirow{2}{*}{ Continuous } & Death rate & $+1.46 \%$ & $+1.59 \%$ & $+2.93 \%$ & $+8.15 \%$ \\
\cline { 2 - 6 } & Median time of death & $-6.25 \%$ & $-6.85 \%$ & $-8.55 \%$ & $-10.6 \%$ \\
\cline { 2 - 6 } & Relative std & $-57.9 \%$ & $-53.3 \%$ & $-34.1 \%$ & $-18.3 \%$ \\
\hline Pulse & Death rate & $+11.7 \%$ & $+13.5 \%$ & $+19.0 \%$ & $+35.2 \%$ \\
\cline { 2 - 6 } & Median time of death & $+0.99 \%$ & $+0.37 \%$ & $+3.27 \%$ & $+3.52 \%$ \\
\cline { 2 - 6 } & Relative std & $+3.84 \%$ & $+8.91 \%$ & $-2.72 \%$ & $-0.80 \%$ \\
\hline
\end{tabular}

Comparison of NF- $\kappa \mathrm{B}$ knockout cells and wild type cells for different stimulations (continuous and 30 minute pulse of TNF at concentrations of 1,3 , 10 or 30 ng/ $\mathrm{ml}$ ). Death rate, median time of death and standard deviation normalized by the median (relative std) are shown here for the knockout cells normalized by the corresponding wild type cell value.

A20, BAR and XIAP. For all of them, the magnitude of the sensitivity was smaller for pulse stimulation compared to continuous stimulation.

\section{NF- $\kappa$ B Module Enhances Heterogeneity}

The sensitivity analysis suggested that the NF- $\kappa \mathrm{B}$ module was irrelevant for the timing of death, see Figure $4 \mathrm{C}$ and 4D. To confirm or refute this hypothesis, we studied the importance of the NF- $\kappa \mathrm{B}$ pathway by comparing "wild type" cells to cells manipulated in silico to show no TNF induced NF- $\kappa \mathrm{B}$ activation. Mathematically, NF- $\kappa \mathrm{B}$ knockout cells were modeled by setting the rate of the irreversible reaction release and degradation of bound $\mathrm{I} \kappa \mathrm{B} \alpha \mathrm{IKKa}+\mathrm{I} \kappa \mathrm{B} \alpha: \mathrm{NF}-\kappa \mathrm{B} \rightarrow \mathrm{IKKa}+\mathrm{NF}-\kappa \mathrm{B}+$ $\mathrm{PI} \kappa \mathrm{B} \alpha$ to zero.

For continuous stimulation, a higher dose led to earlier death and the NF- $\kappa$ B knockout cells died earlier than the wild type ones, especially for low dosage concentrations (Figure 5C). The reduced standard deviation, in particular, revealed much more homogeneous behavior for the knockout cells than for the wild type cells (Figure 5D and Table 1). For pulse stimulation, the survival rate was significantly dosage dependent (data not shown) and wild type cells were more protected from death (Table 1).

\section{Discussion}

The dose-response relationship of TNF induced signaling follows an intricate pattern. Low TNF concentrations barely induce any system response. For high TNF concentrations, the system is insensitive to stimulus changes due to receptor saturation. In between, especially in the range of $1-10 \mathrm{ng} / \mathrm{ml}$ TNF, small stimulus changes can lead to different phenotypes, or at least have a significant impact on timing and amplitude of the signaling processes. The precise knowledge of this window of high cellular sensitivity to changes in stimulus strength is of particular interest for the development of therapeutic strategies.

Heterogeneity within a clonal cell population is an essential property of many biological signaling mechanisms, as is also the case for apoptosis signaling. After an extracellular stimulus, the final decision of cellular death versus survival deterministically depends on each particular cell's epigenetic state. While some cells quickly undergo apoptosis, others only slowly develop the final destructive program and therefore the time of death within the whole population is spread over many hours. One particular group of cells even survives the stimulus that is lethal to other cells. This corresponds to the observed partial TNF resistance, where the level of resistance is dependent on time and stimulus dosage. This observed cell to cell heterogeneity can well be described by cell ensemble models as demonstrated with the proposed model as well as by others.

Global sensitivity analysis revealed that out of all protein production rates those of BAR and XIAP had, by far, the highest positive correlation with the time of death, i.e. overexpressing these caspase inhibitors delayed cell death significantly. Procaspase-8, TNFReceptor, TRAF2, RIP and Procaspase- 3 were the most sensitive parameters showing a negative correlation, thus their increase advances cell death.

A comparison of the sensitivities of the cell population with the nominal cell reveals a much lower sensitivity to parametric variations of the cell population. The sensitivity is also enhanced in NF- $\kappa \mathrm{B}$ knockout cells even though the model shows that the time of death is insensitive to the parameters of the NF- $\kappa \mathrm{B}$ module. Thus, our analysis reveals a hidden advantage of heterogeneous populations resulting in a lower sensitivity to parameter variations.

\section{Conclusion}

This paper highlights the complexity of analyzing the sensitivity of cell population models. The proposed global sensitivity analysis method allowed for a quantification of the importance of the population parameters within the heterogeneous cell population. The analysis results were dependent on the input signal, i.e. its intensity and duration. The heterogeneity within a cell 


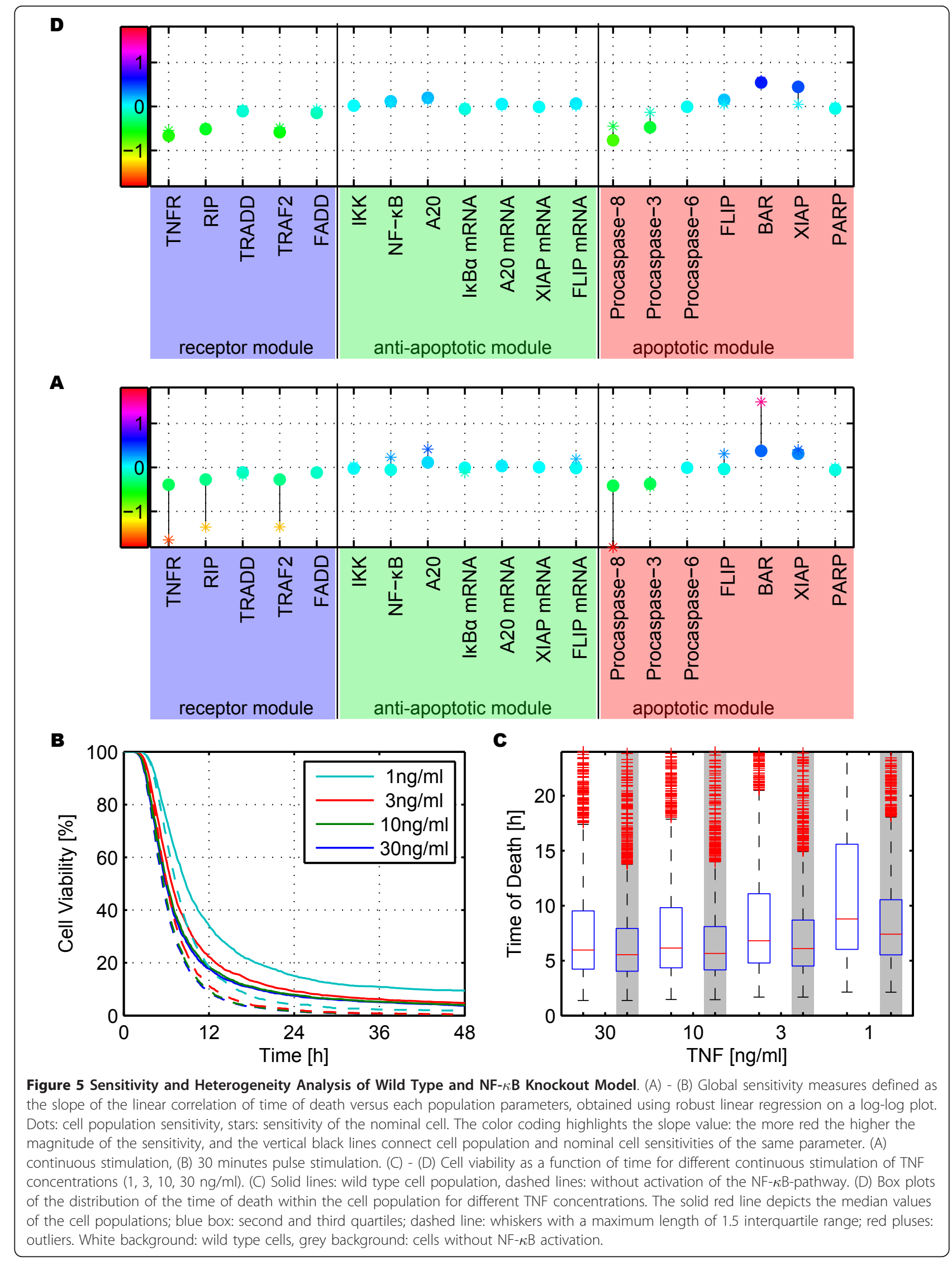


population was shown to reduce the sensitivity as determined by a global sensitivity analysis of the time of death. Even though the NF- $\kappa$ B module seemed unimportant from a sensitivity analysis point of view, it not only increases the expression of anti-apoptotic proteins, but also enhances the heterogeneity.

In summary, the higher computational effort of calculating the sensitivity for a cell population, as opposed to a single cell, is necessary in order to understand the importance of the different parameters.

\section{Methods}

\section{Cell Culture, Stimulation and Plasmids}

The human rhabdomyosarcoma cell line KYM-1 was kindly provided by Dr. M. Sekiguchi, University of Tokyo, Japan [36]. Cells were maintained in RPMI 1640 supplemented with L-Glutamine and 10\% heat inactivated fetal calf serum (FCS) and splitted every 2-3 days. All experiments were carried out using the TNF-R1 selective TNF mutant CysHisR32W/S86T-TNF, here referred to as TNF [37-39]. For pulse stimulations, TNF was removed after 30 minutes by three washes with RPMI medium. Subsequently, fresh culture medium was added. Controls revealed that this washing procedure was highly effective to remove all free TNF. For continuous stimulations, no fresh TNF and culture medium were added. The plasmid pEGFP-p65 was kindly provided by Dr. J. A. Schmid, University of Vienna [40].

\section{Preparation of Nuclear Protein Extracts}

$10^{6} \mathrm{KYM}-1$ cells were seeded in 6 -well plates, cultivated over night and stimulated the following day as mentioned for each experiment. Nuclear protein extracts were obtained by lysing the cells [41]. Total protein concentrations were determined with the Bradford protein assay reagent (Protein Assay, BioRad, Hercules, USA) and photometric extinction measurement at $595 \mathrm{~nm}$. For all samples, identical protein amounts were employed.

\section{Electrophoretic Mobility Shift Assays (EMSAs)}

Nuclear protein extracts were subjected to EMSAs with $\left[\gamma-{ }^{32} \mathrm{P}\right]$-ATP end-labeled oligonucleotides with one NF$\kappa \mathrm{B}$ binding site (5'-AGTTGAGGGGACTTTCCCAGG$\left.3^{\prime}\right)$. Ten micrograms of each probe were incubated with $4 \mu \mathrm{g}$ poly dI-dC (GE Healthcare, Uppsala, Sweden) for 15 minutes at room temperature and thereafter with radioactively labeled oligonucleotides for 10 minutes. After addition of the DNA sample buffer, EMSA was performed in a $6 \%$ polyacrylamide gel for 90 minutes at $22 \mathrm{~mA}$. Vacuum dried gels were exposed to an X-ray screen over night, the autoradiographs were scanned (Molecular Probes Storm 860 Phosphoreader, Invitrogen, Carlsbad, USA). Oct-1 served as a loading control.

\section{Caspase Activity Assays}

KYM-1 cells $\left(5 \cdot 10^{5} /\right.$ well $)$ were seeded and cultivated overnight in 6-well plates. After 4, 5, 6 or 8 hours incubation time with $1 \mathrm{ng} / \mathrm{ml} \mathrm{TNF}$, cytoplasmatic cell lysates were obtained. As control experiments, the same stimulation was performed on cells preincubated with $20 \mu \mathrm{M}$ Z-VAD-fmk. On ice, $15 \mu \mathrm{g}$ total protein in a volume of $20 \mu \mathrm{l}$ were added to $125 \mu \mathrm{l}$ caspase activity buffer, containing the protease inhibitor Complete $(1 x)$ and the reducing agent DTT $(1 \mu \mathrm{M}$ final concentration) and 1 $\mu$ l Caspase- 3 substrate AC-DEVD-AMC. Samples were measured by using an automated fluorimeter (Tecan Infinite M200) at $37^{\circ} \mathrm{C}$ for 2 hours, in which emission was measured in 2 minute intervals, at wavelengths of $380 \mathrm{~nm}$ (excitation) and $460 \mathrm{~nm}$ (emission). Caspase amount was quantified as the median value of each slope.

\section{Cytotoxicity Assays}

KYM- 1 cells $\left(10^{4} /\right.$ well $)$ were seeded and cultivated overnight in 96-well microtiter plates (Greiner Bio-One $\mathrm{GmbH}$, Frickenhausen, Germany). The next day, cells were treated with serial dilutions of TNF, ranging from 100 to $0.01 \mathrm{ng} / \mathrm{ml}$ for several periods of time. Supernatants were discarded, cells were washed with PBS and cell viability was determined using crystal violet $(\mathrm{CV})$ staining [42]. Background was defined using CV only and was subtracted from the signal. Values were normalized with respect to untreated controls.

\section{Computational Tools}

The nominal, single cell model is available in Systems Biology Markup Language (SBML), see Additional File 3. Simulations were performed with Matlab Version 7.1.0.246 (R14) Service Pack 3 (Mathworks) with the built-in variable order, multistep solver ode15s, which is based on numerical differentiation formulas, as the differential equations are stiff.

The cell ensemble model was obtained by varying all expression rates independently from each other, lognormally distributed with a standard deviation $\sigma=0.148$ and as mean the value of the single cell model. For each sample of the population, the initial condition was the corresponding steady state that has no activated caspases.

Robust linear regression and the estimate of the standard deviation of the error were calculated using the Matlab commands robustfit from the Statistics Toolbox and polyval, respectively.

Direct comparison of simulation with experimental data required their normalization. First, the background intensity of each measurement was determined and subtracted from the data. Measurements with signal intensities lower than the background were set to zero. The 
values were then normalized by the maximum of the time course to obtain relative intensities in the range of 0 to $100 \%$.

\section{Additional material}

Additional file 1: Cytotoxicity Assays. Quantification of cell viability of KYM-1 cells for different TNF concentrations (0-100 ng/ml TNF). The experiments were performed at 5 different times post stimulus (color coded), for continuous (solid lines) and 30 minute pulse (dashed lines) stimulations. Both included error bars from three independent experiments. Figures 2C-D show this data in a 3-D view.

\section{Additional file 2: Detailed Description of the Mathematical Model} and Model Validation. Detailed description of the mathematical model including experimental data for model validation.

Additional file 3: SBML Code of the Nominal Cell Model. SMBL code of the nominal cell model. Also available in the BioModels data base as MODEL1112210000. See http://sbml.org/ for software to simulate or visualize SBML models.

\section{Acknowledgements and funding}

The authors would like to thank Stefanie Braun for the Caspase-3 activity assay, Johan Toloe for the microinjection experiment, Jeannette Skinner for proofreading the manuscript. The authors would also like to acknowledge financial support from Deutsche Forschungsgemeinschaft (DFG) grants BU 1405/1-1 and SCHE 349/8-1. The funders had no role in study design, data collection and analysis, decision to publish, or preparation of the manuscript. The experiments were performed while the first author was a member of the Institute of Cell Biology and Immunology, University of Stuttgart.

\section{Author details}

${ }^{1}$ Institute for Automation Engineering, Laboratory for Systems Theory and Automatic Control, Otto-von-Guericke University Magdeburg, Germany. ${ }^{2}$ Department of Electrical Engineering and Computer Science, Institut Montefiore, Université de Liège, Belgium. ${ }^{3}$ Institute for Systems Theory and Automatic Control, University of Stuttgart, Germany. ${ }^{4}$ Institute of Cell Biology and Immunology, University of Stuttgart, Germany.

\section{Authors' contributions}

MS conceived and carried out all wet-lab experiments as well as the modeling. PS participated in the design of the experimental study. MS and RF conceived the theoretical study. SB collaborated on the cell ensemble modeling. EB performed the model analyses. FA participated in coordinating the study. MS, EB and PS wrote the manuscript. All authors read and approved the final manuscript.

Received: 4 September 2011 Accepted: 28 December 2011 Published: 28 December 2011

\section{References}

1. Yuan J: Divergence from a dedicated cellular suicide mechanism: exploring the evolution of cell death. Mol Cell 2006, 23:1-12.

2. Kerr JF, Wyllie AH, Currie AR: Apoptosis: a basic biological phenomenon with wide-ranging implications in tissue kinetics. Br J Cancer 1972, 26:239-257.

3. Diamantis A, Magiorkinis E, Sakorafas GH, Androutsos G: A brief history of apoptosis: from ancient to modern times. Onkologie 2008, 31:702-706.

4. Opferman JT, Korsmeyer SJ: Apoptosis in the development and maintenance of the immune system. Nat Immunol 2003, 4:410-415.

5. Strasser A, Whittingham S, Vaux DL, Bath ML, Adams JM, Cory S, Harris AW: Enforced $\mathrm{BCL} 2$ expression in B-lymphoid cells prolongs antibody responses and elicits autoimmune disease. Proc Natl Acad Sci USA 1991, 88:8661-8665

6. O'Reilly LA, Strasser A: Apoptosis and autoimmune disease. Inflamm Res 1999, 48:5-21.
7. Troy CM, Salvesen GS: Caspases on the brain. J Neurosci Res 2002, 69:145-150.

8. Thompson CB: Apoptosis in the pathogenesis and treatment of disease. Science 1995, 267:1456-1462.

9. Haass C: Apoptosis. Dead end for neurodegeneration? Nature 1999, 399:204-205, 207.

10. Lockshin RA, Zakeri Z: Programmed cell death and apoptosis: origins of the theory. Nat Rev Mol Cell Biol 2001, 2:545-550.

11. Wajant $H$, Pfizenmaier $K$, Scheurich P: Tumor necrosis factor signaling. Cell Death Differ 2003, 10:45-65.

12. Baud V, Karin M: Signal transduction by tumor necrosis factor and its relatives. Trends Cell Biol 2001, 11:372-377.

13. Micheau O, Tschopp J: Induction of TNF receptor I-mediated apoptosis via two sequential signaling complexes. Cell 2003, 114:181-190.

14. Schneider-Brachert W, Tchikov V, Neumeyer J, Jakob M, Winoto-Morbach S, Held-Feindt J, Heinrich M, Merkel O, Ehrenschwender M, Adam D, et al: Compartmentalization of TNF receptor 1 signaling: internalized TNF receptosomes as death signaling vesicles. Immunity 2004, 21:415-428.

15. Grell M, Douni E, Wajant H, Löhden M, Clauss M, Maxeiner B, Georgopoulos S, Lesslauer W, Kollias G, Pfizenmaier K, Scheurich P: The transmembrane form of tumor necrosis factor is the prime activating ligand of the 80 kDa tumor necrosis factor receptor. Cell 1995, 83:793-802.

16. Grell M, Zimmermann G, Gottfried E, Chen CM, Grunwald U, Huang DC, Wu Lee $\mathrm{YH}$, Durkop $H$, Engelmann $H$, Scheurich $P$, et al: Induction of cell death by tumour necrosis factor (TNF) receptor 2, CD40 and CD30: a role for TNF-R1 activation by endogenous membrane-anchored TNF. EMBO J 1999, 18:3034-3043.

17. Scaffidi C, Fulda S, Srinivasan A, Friesen C, Li F, Tomaselli KJ, Debatin KM, Krammer PH, Peter ME: Two CD95 (APO-1/Fas) signaling pathways. EMBO J 1998, 17:1675-1687

18. Grell M, Zimmermann G, Hulser D, Pfizenmaier K, Scheurich P: TNF receptors TR60 and TR80 can mediate apoptosis via induction of distinct signal pathways. J Immunol 1994, 153:1963-1972.

19. Rehm M, Dussmann H, Janicke RU, Tavare JM, Kogel D, Prehn JH: Singlecell fluorescence resonance energy transfer analysis demonstrates that caspase activation during apoptosis is a rapid process. Role of caspase3. J Biol Chem 2002, 277:24506-24514.

20. Spencer SL, Gaudet S, Albeck JG, Burke JM, Sorger PK: Non-genetic origins of cell-to-cell variability in TRAIL-induced apoptosis. Nature 2009, 459:428-432.

21. Gatenby RA, Silva AS, Gillies RJ, Frieden BR: Adaptive therapy. Cancer Res 2009, 69:4894-4903.

22. Hawkins ED, Turner ML, Dowling MR, van Gend C, Hodgkin PD: A model of immune regulation as a consequence of randomized lymphocyte division and death times. Proc Natl Acad Sci USA 2007, 104:5032-5037.

23. Yeyati $\mathrm{PL}$, van Heyningen $\mathrm{V}$ : Incapacitating the evolutionary capacitor: Hsp90 modulation of disease. Curr Opin Genet Dev 2008, 18:264-272.

24. Tomlin CJ, Axelrod JD: Biology by numbers: mathematical modelling in developmental biology. Nat Rev Genet 2007, 8:331-340.

25. Cohen AA, Geva-Zatorsky N, Eden E, Frenkel-Morgenstern M, Issaeva I, Sigal A, Milo R, Cohen-Saidon C, Liron Y, Kam Z, et al: Dynamic proteomics of individual cancer cells in response to a drug. Science 2008, 322:1511-1516.

26. Sillitoe $K$, Horton C, Spiller DG, White MRH: Single-cell time-lapse imaging of the dynamic control of NF-kB signalling. Biochem Soc Trans 2007, 35:263-266.

27. Eissing $T$, Conzelmann $H$, Gilles ED, Allgöwer F, Bullinger $E$, Scheurich P: Bistability analyses of a caspase activation model for receptor-induced apoptosis. J Biol Chem 2004, 279:36892-36897.

28. Sigal A, Milo R, Cohen A, Geva-Zatorsky N, Klein Y, Liron Y, Rosenfeld N, Danon T, Perzov N, Alon U: Variability and memory of protein levels in human cells. Nature 2006, 444:643-646.

29. Gsponer J, Futschik ME, Teichmann SA, Babu MM: Tight regulation of unstructured proteins: from transcript synthesis to protein degradation. Science 2008, 322:1365-1368.

30. Kollmann $M$, Sourjik $\mathrm{V}$ : In silico biology: from simulation to understanding. Curr Biol 2007, 17:R132-R134

31. Neumann L, Pforr C, Beaudouin J, Pappa A, Fricker N, Krammer PH, Lavrik IN, Eils R: Dynamics within the CD95 death-inducing signaling complex decide life and death of cells. Mol Syst Biol 2010, 6:352. 
32. Lazebnik Y: Can a biologist fix a radio?-Or, what I learned while studying apoptosis. Cancer Cell 2002, 2:179-182.

33. Huber H, Bullinger E, Rehm M: Systems Biology Approaches to the Study of Apoptosis. In Essentials of Apoptosis.. 2 edition. Edited by: Yin X-M, Dong Z. Humana press; 2009:283-297.

34. Domach MM, Shuler ML: A finite representation model for an asynchronous culture of E. coli. Biotechnol Bioeng 1984, 26:877-884

35. Henson MA, Müller D, Reuss M: Cell population modelling of yeast glycolytic oscillations. Biochemical Journal 2002, 368(2):433-446.

36. Sekiguchi M, Shiroko Y, Suzuki T, Imada M, Miyahara M, Fujii G: Characterization of a human rhabdomyosarcoma cell strain in tissue culture. Biomed Pharmacother 1985, 39:372-380.

37. Van Ostade X, Vandenabeele P, Everaerdt B, Loetscher H, Gentz R, Brockhaus M, Lesslauer W, Tavernier J, Brouckaert P, Fiers W: Human TNF mutants with selective activity on the p55 receptor. Nature 1993, 361:266-269.

38. Loetscher H, Stueber D, Banner D, Mackay F, Lesslauer W: Human tumor necrosis factor a (TNF a) mutants with exclusive specificity for the 55kDa or 75-kDa TNF receptors. J Biol Chem 1993, 268:26350-26357.

39. Krippner-Heidenreich A, Tubing F, Bryde S, Willi S, Zimmermann G, Scheurich P: Control of receptor-induced signaling complex formation by the kinetics of ligand/receptor interaction. J Biol Chem 2002, 277:44155-44163.

40. Schmid JA, Birbach A, Hofer-Warbinek R, Pengg M, Burner U, Furtmuller PG, Binder $B R$, de Martin R: Dynamics of NF $\mathrm{kB}$ and IKBa studied with green fluorescent protein (GFP) fusion proteins. Investigation of GFP-p65 binding to DNa by fluorescence resonance energy transfer. J Biol Chem 2000, 275:17035-17042.

41. Wadman IA, Osada H, Grutz GG, Agulnick AD, Westphal H, Forster A, Rabbitts TH: The LIM-only protein Lmo2 is a bridging molecule assembling an erythroid, DNA-binding complex which includes the TAL1, E47, GATA-1 and Ldb1/NLI proteins. EMBO J 1997, 16:3145-3157.

42. Bernhardt $G$, Reile $H$, Birnbock $H$, Spruss $T$, Schonenberger $H$ : Standardized kinetic microassay to quantify differential chemosensitivity on the basis of proliferative activity. J Cancer Res Clin Oncol 1992, 118:35-43.

doi:10.1186/1752-0509-5-204

Cite this article as: Schliemann et al: Heterogeneity reduces sensitivity of cell death for TNF-Stimuli. BMC Systems Biology 2011 5:204.

\section{Submit your next manuscript to BioMed Central and take full advantage of:}

- Convenient online submission

- Thorough peer review

- No space constraints or color figure charges

- Immediate publication on acceptance

- Inclusion in PubMed, CAS, Scopus and Google Scholar

- Research which is freely available for redistribution

Submit your manuscript at www.biomedcentral.com/submit 